\title{
Narrativas sobre diversidad cultural y migración en escuelas de Chile
}

Narratives on Cultural Diversity and Migration in Chilean Schools

Artículo de investigación | Research article

Fecha de recepción: 20 de diciembre de 2018

Fecha de aceptación: 09 de julio de 2019

Fecha de disponibilidad en línea: enero de 2021

doi: 10.11144/Javeriana.m14.ndcm

María Fernanda Stang-Alva ferstang@yahoo.com.ar Universidad Católica Silva Henríquez, Chile https://orcid.org/0000-0003-3781-3024

(iD) ORCID

Andrea Maureen Riedemann-Fuentes andreariedemann@gmail.com Pontificia Universidad Católica de Chile, Chile https://orcid.org/0000-0003-3604-1771

(iD) ORCID
Carolina Stefoni-Espinoza cstefoni@gmail.com UniversidAd MAYOR, ChILE https://orcid.org/0000-0001-6949-2312

(iD) ORCID

Javier Corvalán-Rodríguez jcorvala@uahurtado.cl

Universidad Alberto Hurtado, Chile https://orcid.org/0000-0002-3782-8376

(iD) ORCID

Para citar este artículo | To cite this article Stang-Alva, M. F., Riedemann-Fuentes, A. M., Stefoni-Espinoza, C. \& CorvalánRodríguez, J. (2021). Narrativas sobre diversidad cultural y migración en escuelas de Chile. magis, Revista Internacional de Investigación en Educación, 14, 1-32. doi: 10.11144/Javeriana.m14.ndcm 


\title{
Resumen
}

Este artículo de investigación explora, desde la interculturalidad crítica, los principales enunciados de las tramas narrativas de diferentes actores escolares chilenos (docentes, asistentes y directores) con respecto a los desafíos que la multiculturalidad representa para su práctica pedagógica, a partir de un estudio cualitativo desarrollado en cinco escuelas de tres comunas de la Región Metropolitana (Independencia, Recoleta y Quilicura). Se identifican enunciados enmarcados en dos tipos generales de discurso: uno asimilacionista y universalizador, y otro de la tolerancia y la hibridez. Se concluye que ambos suponen una mirada funcional de la interculturalidad que es preciso problematizar, considerando las prácticas pedagógicas en que se materializan.

\section{Palabras clave}

Chile; diversidad cultural; educación; interculturalidad crítica; investigación participativa; migración

\begin{abstract}
This article explores from the critical interculturality the main tenets of the narrative accounts by different school actors in Chile (teachers, assistants, directors) regarding the challenges that the multiculturality poses to the teaching practice. This work is based on a qualitative study developed in five schools in three different neighborhoods of the Metropolitan Area (Independencia, Recoleta and Quilicura). The tenets identified are framed under two general discursive types: a first one, driven towards assimilation and universalization; a second one, related to the tolerance and hybridity. It is concluded that both types provides a functional view of the interculturality that must be questioned by taking into consideration the pedagogical practices where they become materialized.
\end{abstract}

\section{Keywords}

Chile; cultural diversity; education; critical interculturality; participatory research; migration 
Descripción del artículo | Article description

Este artículo de investigación surge de la investigación

Construyendo escuelas interculturales: elaboración

participativa de una hoja de ruta para asistentes de la

educación, profesores y directivos, financiada por el Ministerio

de Educación (Mineduc) de Chile, mediante el Fondo de

Investigación y Desarrollo en Educación (FX11622, 2016).

\section{Introducción}

Aunque la inmigración internacional no es un proceso social novedoso para Chile, en los últimos años ha experimentado un incremento significativo en el país y, sobre todo, cambios cualitativos que, probablemente, expliquen en parte las razones y la forma de su tematización pública. El consecuente aumento y la diversificación de la llegada de niños, niñas y adolescentes migrantes al sistema escolar chileno han generado muchas preguntas acerca de cómo abordar el proceso de enseñanza-aprendizaje en este contexto de creciente visibilización de la multiculturalidad.

En ese escenario las nociones de multi e interculturalidad han comenzado a emerger como enunciados en las narrativas de diferentes actores, apropiadas de diversas formas en distintos espacios institucionales, pero especialmente en aquellas escuelas que se han visto interpeladas por la realidad de matrículas cada vez más heterogéneas en términos de nacionalidad'. Estas apropiaciones, además, no necesariamente se conectan con el modo en que la interculturalidad se ha institucionalizado en el sistema educativo chileno, al alero del Programa de Educación Intercultural Bilingüe (PEIB), el cual pone su foco en las lenguas y culturas indígenas.

El objetivo de este artículo es, por lo tanto, explorar los principales enunciados que estructuran las tramas narrativas de diversos actores de escuelas públicas de la Región Metropolitana con presencia significativa de estudiantes migrantes en sus matrículas, acerca de los desafíos que la

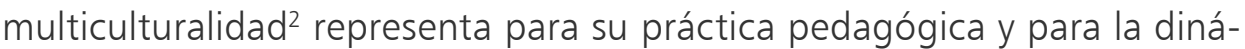
mica de su comunidad educativa en general. Los actores considerados para

1 Es importante aclarar que el peso de los estudiantes extranjeros sobre el total de la matrícula nacional no es relevante en términos cuantitativos: 2,2\% en 2017 (Fernández, 2018). Sin embargo, se registran concentraciones importantes en determinadas regiones del país (principalmente las tres del Norte Grande: Arica y Parinacota, Tarapacá y Antofagasta, con el $8 \%$, el $14 \%$ y el $11 \%$, respectivamente, seguidas de la Región Metropolitana, con el $7 \%$ ), en algunas comunas en particular, y, dentro de ellas, en algunas escuelas puntualmente.

2 Entendida en este caso en sentido descriptivo, y asociada a la diversidad migratoria. 
ello fueron profesores, asistentes de la educación y directivos, así como las autoridades de los departamentos de educación municipal, de establecimientos de las comunas de Independencia, Recoleta y Quilicura, en la Región Metropolitana. El propósito de este texto parte del supuesto de que el modo en que estos actores de las comunidades educativas están comprendiendo este proceso social se materializa en la práctica pedagógica de los docentes y asistentes. Por lo tanto, conocer estos discursos es un primer paso necesario y relevante para generar transformaciones que permitan avanzar hacia la implementación de una educación intercultural desde una perspectiva crítica, horizonte desde el que se desarrolló este estudio.

Aunque ni a nivel nacional ni internacional existe un consenso acabado sobre el significado del término interculturalidad, consideramos que el concepto de interculturalidad crítica (Tubino, 2005; Walsh, 2011), desarrollado en el contexto latinoamericano en atención a las huellas del colonialismo (Quijano, 2000) en el continente, representa una contribución fundamental en el debate sobre la diversidad cultural. Por lo tanto, desde esa perspectiva teórica, epistemológica y política realizamos el análisis propuesto.

La estructura del artículo inicia con un apartado de antecedentes, centrado en contextualizar la vinculación reciente de la interculturalidad con la migración en América Latina y en explicitar el marco conceptual que orientó el análisis. Los dos siguientes apartados describen brevemente las comunas y escuelas que fueron escenario del trabajo de campo y los aspectos metodológicos de la investigación. Paso seguido, se exponen los resultados, describiendo los principales enunciados identificados, y posteriormente se los analiza, proponiendo que estos pueden agruparse en dos tipos principales de discursos, que se discuten desde el enfoque de la interculturalidad crítica. En el apartado final se exponen reflexiones centradas en algunos silencios de estos discursos que nos parecen relevantes desde la perspectiva teórica adoptada.

\section{La educación intercultural en América Latina: antecedentes y marco conceptual}

La literatura sobre el tema ubica la emergencia de la noción de interculturalidad en nuestra región en la década de 1970, sobre todo en el ámbito educativo, y en vinculación estrecha con la educación escolar indígena (Ferrão Candau, 2010; López, 2001), casi exclusivamente relacionada al bilingüismo (educación intercultural bilingüe, EIB o EBI): "En América Latina la discusión suele centrarse en espacios en los que la diversidad cultural está definida por la diferenciación étnica, en términos de población indígena o 
pueblos originarios, vinculando frecuentemente categorías estáticas y esencialistas de identidad y cultura" (Diez, 2004, p. 191).

La tematización de la interculturalidad en la región comienza a generarse desde los movimientos indígenas más consolidados, y en algunos países también desde los afrodescendientes; se reconoce, además, la influencia de los planteos de la educación popular. Luego de esta génesis, la problematización sobre el abordaje de la diversidad cultural desde el enfoque de la interculturalidad salta a los escenarios políticos nacionales en la década de 1980, pero fundamentalmente durante la de 1990 (Rodríguez-Cruz, 2016), institucionalizándose incluso en varias reformas constitucionales (como las de Colombia, Ecuador y Bolivia). La aproximación académica al tema, en tanto, comienza a crecer a fines de los años noventa, y se intensifica desde la década de 2000, con un rico debate y aportes críticos muy agudos.

La vinculación casi exclusiva de los desarrollos conceptuales y debates en torno a la interculturalidad con la cuestión indígena durante las primeras décadas diferencia a América Latina ${ }^{3}$ con respecto a lo ocurrido en Europa, a pesar de que la discusión sobre este tema es contemporánea:

La propuesta latinoamericana de educación intercultural guarda ahora alguna similitud con lo que, bajo el mismo término, se postula en algunos países europeos, como Alemania, España, Gran Bretaña, Holanda y Suecia, para abordar la situación derivada de la migración del Tercer Mundo hacia Europa y en respuesta a la xenofobia y al racismo que reaparecen en ese continente. De hecho, [...] la adopción del término, así como las propuestas europeas de interculturalidad, son prácticamente coetáneas con las sudamericanas (López, 2001, p. 390).

De este modo, la vinculación del concepto de interculturalidad con el foco en los pueblos indígenas tiene una importante trayectoria en la región, pero la relación de este concepto con los procesos migratorios es aún incipiente. Las razones de ello parecen bastante claras: durante el último medio siglo, América Latina ha sido una región de emigración en términos agregados, lo que se ha debido sobre todo a situaciones de pobreza estructural y de violencia política, representadas, por ejemplo, por las dictaduras que sufrieron países como Argentina, Brasil, Chile y Uruguay a partir de la década de 1960. Las excepciones dentro de este contexto regional marcado por la emigración estuvieron dadas solo por algunos casos, como los de

3 Y también a otros contextos, como el canadiense. 
Argentina, Venezuela en algún momento o Costa Rica ${ }^{4}$. Por otra parte, desde la década de 1970, la composición de la población inmigrante regional ha registrado un incremento de los países latinoamericanos (de un $24 \%$ en 1970 a un $63 \%$ en 2010), es decir, la mayor parte de los migrantes que llegan son también latinoamericanos, lo que supone una matriz cultural semejante, y en muchos casos el mismo idioma, un elemento que imprime particularidades a este escenario ${ }^{5}$. No estamos sosteniendo con esto que el enfoque intercultural solo se justifique en situaciones de "mayor distancia cultural", sino que el recurso a estas herramientas se tematiza más en esos escenarios.

El puente reciente entre los planteos de la educación intercultural y la migración internacional se ha estado desarrollando entonces en algunos escenarios nacionales específicos, ya sean históricamente receptores de población extranjera, como el argentino o el costarricense (Jiménez, 2012; Neufeld \& Thisted, 1999; Novaro, 2011; Smith-Castro, Araya \& Peña, 2009), o bien destinos emergentes, como Chile. En este último caso, la llegada de población afrodescendiente de América Latina y del Caribe, sobre todo, y alguna que habla otras lenguas — como el creole — han puesto en evidencia las limitaciones de un abordaje intercultural ligado exclusivamente a la población indígena y que no se hace cargo del racismo estructural de la sociedad chilena (Tijoux, 2016). Por lo demás, este abordaje ya venía siendo cuestionado incluso en su aproximación a los pueblos originarios (Lagos, 2015; Montecinos, 2004; Riedemann, 2008). Por lo tanto, este es un escenario propicio para investigar y reflexionar en este ámbito temático, partiendo por preguntarnos por las razones de la emergencia de esta necesidad de reformular el enfoque intercultural de la política educativa chilena en este momento histórico y en este contexto, y reflexionando acerca de qué nos habla esta emergencia en el discurso social.

Resulta interesante cuestionarse por qué esta necesidad no se planteó antes, por ejemplo, a partir de la presencia histórica de estudiantes bolivianos y peruanos en las escuelas públicas del norte del país. O por qué la respuesta de política educativa frente a la inmigración intrarregional reciente

4 Según los últimos datos censales, los emigrados representan un 4,8\% de la población latinoamericana, mientras que los inmigrantes el 1,3\%, y de los 21 países que conforman la región, solo 6 presentan la situación contraria, es decir, registran mayor representación los inmigrantes que los emigrantes (Argentina, Costa Rica, Venezuela, Guayana Francesa, Suriname y Belice) (Martínez \& Orrego, 2016). Hay que considerar, de todos modos, que estos datos son previos a la situación migratoria venezolana más reciente.

5 En Europa, por ejemplo, la mitad de la migración internacional también es intrarregional (Organización Internacional para las Migraciones, 2017), pero no se da esta particularidad de una importante homogeneidad idiomática. 
ha tenido un carácter asimilacionista principalmente, mientras que en la época de la inmigración europea (siglo XIX y comienzos del XX) el modo de abordaje de esta diversidad derivó en la creación de escuelas de colonias, de carácter privado, es decir, una autosegregación, no cuestionada desde el Estado. Encontrar respuestas a estas preguntas exigiría una investigación específica sobre el tema; sin embargo, plantear los interrogantes permite reflexionar sobre el trasfondo del modo en que los actores del sistema educativo chileno experimentan el desafío de la presencia de estos estudiantes migrantes en sus aulas.

\section{La interculturalidad decolonial como horizonte teórico}

En América Latina es imposible pensar la interculturalidad desvinculada de la experiencia de colonialidad, es decir, de ese "complejo proceso de estructuración de relaciones de poder que, mediante la naturalización de todo tipo de jerarquías (desde las raciales hasta las epistémicas), garantiza la reproducción y la legitimación de desigualdades entre sociedades, sujetos y conocimientos" (Soria, 2014, p. 47). Desde esa certeza, el lugar teórico y político desde el que se realizó este estudio, y desde el que se elaboraron los análisis que se presentan en este artículo, es el de la interculturalidad decolonial o crítica (Walsh, 2002; 2009; 2011). La especificación de este doble lugar de enunciación (teórico y político) se relaciona con los elementos de investigación-acción participativa presentes en el trabajo de campo y con el hecho de que el horizonte del estudio fue contribuir en alguna medida con la adopción de una educación intercultural crítica en las escuelas.

Catherine Walsh (2011) distingue tres perspectivas dentro de la interculturalidad: la relacional, la funcional y la crítica. La primera se refiere "al contacto e intercambio entre culturas, es decir, entre personas, prácticas, saberes, valores y tradiciones culturales distintas, los que podrían darse en condiciones de igualdad o desigualdad" (p. 101). Alude, por lo tanto, a una realidad de hecho en América Latina. Por su parte, la perspectiva funcional, según la ha caracterizado Fidel Tubino (2005), promueve el diálogo, la convivencia y la tolerancia entre culturas, pero sin cuestionar las causas de la asimetría y desigualdad social y cultural. La interculturalidad crítica, en cambio, no parte del problema de la diversidad sino del de la diferencia, construida dentro de una "estructura y matriz colonial de poder racializado y jerarquizado" (Walsh, 2011, p. 102). Esta perspectiva apunta a una transformación de esas estructuras, instituciones y relaciones sociales, y a "la construcción de condiciones de estar, ser, pensar, conocer, aprender, sentir y vivir distintas" (Walsh, 2011, p. 102).

Las discusiones sobre interculturalidad en América Latina, en efecto, se organizan en buena medida en torno al eje determinado por las tensiones 
entre diversidad y desigualdad (Ferrão-Candau, 2010; Soria, 2014; Tubino, 2005; Walsh, 2002). Guilherme \& Dietz (2014), por ejemplo, distinguen tres tipos de paradigmas en el estudio de la diversidad y la desigualdad en la región: el de la desigualdad, el de la diferencia y el de la diversidad. El paradigma de la desigualdad genera, según los autores, respuestas compensatorias, muchas veces abiertamente asimilacionistas, y representan "un enfoque universalista, profundamente arraigado teórica y programáticamente a un habitus monolingüe y monocultural [...], resultado del Estado-nación occidental y su manera hegemónica de concebir las ciencias sociales" (Guilherme \& Dietz, 2014, p. 31). El paradigma de la diferencia "privilegia las respuestas particularistas y multiculturalistas que a menudo ignoran, invisibilizan o minimizan las desigualdades y las condiciones estructurales socioeconómicas" (Guilherme \& Dietz, 2014, p. 31). Los tipos de discurso identificados a partir de las tramas narrativas de los actores de las comunidades educativas con las que se trabajó se emparentan con ambos paradigmas, como se verá más adelante. El tercer paradigma identificado por los autores, el de la diversidad, debiese "enfatizar la interacción que se produce entre dimensiones identitarias sumamente heterogéneas" (de clase, cultural, étnica, religiosa, de clase o de género) (Guilherme \& Dietz, 2014, p. 32). A esa heterogeneidad necesita prestar atención una escuela intercultural desde una perspectiva crítica, según entendemos, pues es en la intersección de esas dimensiones que las diferencias se transforman en desigualdades.

En ese sentido, hay una coincidencia significativa en la literatura regional crítica sobre el tema con respecto a que en nuestra región ha habido una subordinación histórica que ha transformado las diferencias culturales en desigualdades, el colonialismo. Por lo tanto, desde la propuesta de la interculturalidad crítica, "no se trata tanto de encontrar la mejor forma de incluir grupos históricamente negados en los marcos político-institucionales vigentes como sí de generar un proceso de crítica y transformación de las lógicas de estructuración de relaciones sociales" (Soria, 2014, p. 51). Esto es, precisamente, a lo que apunta la propuesta epistemológico-política de la interculturalidad decolonial: se trataría de un horizonte normativo, algo por construir; una propuesta de acción política, que enfoca los procesos que se inician desde abajo hacia arriba (Walsh, 2002). Por eso justamente es que Walsh prefiere hablar de interculturizar antes que de interculturalidad.

Es entonces desde este referente conceptual que en este artículo nos preguntamos por los principales enunciados que organizan las tramas narrativas sobre los desafíos que implica la multiculturalidad para diversos actores de escuelas públicas de la Región Metropolitana con presencia significativa de estudiantes migrantes. Cuáles son esos enunciados y qué 
representaciones les subyace sobre los modos posibles de abordar la diversidad cultural asociada a la migración en las escuelas son las preguntas que orientan el análisis que se propone en este artículo. Ese análisis parte del entendido de que esas representaciones se materializan en las prácticas pedagógicas de estos actores fundamentales, y que, para avanzar hacia una escuela intercultural crítica, es fundamental transformar esas miradas.

\section{El escenario del estudio}

El trabajo de campo se realizó en cinco escuelas municipales de la Región Metropolitana durante 2017. Según el censo abreviado de ese mismo año, esta región es la que presenta mayor proporción de población migrante a nivel nacional, con respecto al total de migrantes internacionales (486568 personas, 65,2\%), y es la cuarta en relación con el total de la población regional (7\%). Se trata fundamentalmente de migración intrarregional: peruanos (29,4\%), venezolanos (14,2\%), colombianos $(12,8 \%)$ y haitianos $(11,2 \%)$ son los cuatro grupos mayoritarios. El $14,5 \%$ de esta población migrante regional tiene entre 0 y 19 años, es decir, es población en edad escolar. Si bien la presencia de esta migración en la región comenzó a incrementarse desde mediados de la década de 1990, ha sido en el último quinquenio que ese crecimiento se ha intensificado y diversificado en términos de países de origen.

El criterio preliminar establecido para la selección de las comunas y los establecimientos en los que se realizó el trabajo de campo fue la alta presencia de estudiantes migrantes (tabla 1). En efecto, las comunas a las que pertenecen las escuelas también se caracterizan por su significativa presencia de población migrante: $31 \%$ en el caso de Independencia, $16 \%$ en el de Recoleta y $8 \%$ en Quilicura. En este último caso, se contempló, además, la concentración de migración haitiana, que representa el 52,8\% de la población migrante internacional de esa comuna, lo que implica desafíos específicos para las escuelas, dada la diferencia lingüística.

En el la figura 1 puede observarse la ubicación de las comunas seleccionadas en el contexto de la Región Metropolitana (situada en el centro del país), y a partir de la referencia de la comuna de Santiago, sede del Poder Ejecutivo nacional. La concentración de la población migrante principalmente en Independencia y Recoleta se relaciona sobre todo con esta cercanía, en el marco de un patrón nacional de distribución territorial muy centralizado, que la población migrante ha tendido a reproducir. La localización de migrantes haitianos en la comuna de Quilicura, por tanto, está relacionada sobre todo con su política migratoria municipal y con la conformación de redes migratorias. 
Tabla 1

Matrícula total y porcentaje de alumnos extranjeros de las escuelas de la muestra, 2016

\begin{tabular}{l|c|c}
\hline Escuela & Matrícula total & Porcentaje (\%) de extranjeros \\
\hline Escuela 1, Independencia & 250 & 12,4 \\
\hline Escuela 2, Independencia & 160 & 45,0 \\
\hline Escuela 3, Recoleta & 1148 & 33,2 \\
\hline Escuela 4, Recoleta & 483 & 46,4 \\
\hline Escuela 5, Quilicura & 870 & 13,0 \\
\hline
\end{tabular}

Nota: Si bien en cada escuela se recabaron datos de la matrícula a 2017, dada la disparidad en el nivel de precisión de los datos, se optó por homogeneizar su presentación a partir del recurso a esta base de datos, excepto en el caso de la escuela 2, que, al tener dependencia administrativa de otro establecimiento, no aparecía desagregada en la base. En ese caso, la información fue provista por la directora, y corresponde a 2017.

Fuente: base de datos de matrículas del Ministerio de Educación (2016)

Figura 1

Chile: comunas de la Región Metropolitana en las que se desarrolló el estudio




Las comunas en las que se desarrolló el trabajo de campo tenían en 2015 entre un $20 \%$ y un $30 \%$ de su población en situación de pobreza multidimensional $^{6}$ (Quilicura, 18,5\%; Independencia, 21,3\%, y Recoleta, $26,2 \%)$, dentro de un rango regional que iba del $2,8 \%$, en el caso de Vitacura, al 42,4\%, en el de La Pintana, según el Observatorio Social del Ministerio de Desarrollo Social y Familia (Observatorio Social, s. f.).

Las cinco escuelas que formaron parte de la muestra, por su parte, registraban en 2016 un índice de vulnerabilidad escolar (IVE) que se concentraba en un rango del $72 \%$ al $88,7 \%$ de sus matrículas, lo que habla de una situación socioeconómica precaria de sus alumnos, que los propios actores entrevistados describieron. El IVE Sinae (Sistema Nacional de Asignación con Equidad) es un indicador que considera condiciones de pobreza y riesgo de fracaso escolar ${ }^{7}$. Es altamente probable que el perfil socioeconómico de las familias migrantes que llevan sus hijos a estas escuelas esté representado en estos indicadores, si se considera que la población migrante de la Región Metropolitana en general está más afectada por la pobreza multidimensional que la población nativa regional (23,8\%, frente a 19,6\%, según la Encuesta de Caracterización Socioeconómica de 2017).

Esta es entonces, a grandes rasgos, la realidad de las escuelas en las que se desarrolló el estudio. De acuerdo con los entrevistados, estos establecimientos tienen un alumnado migrante mayoritariamente latinoamericano: niñas y niños peruanos, colombianos, haitianos (que representan el $80 \%$ del alumnado migrante en la escuela 5), venezolanos, dominicanos, ecuatorianos, bolivianos, paraguayos y argentinos, estos dos últimos con mucho menor presencia. Según explicaron los entrevistados, estos estudiantes residen en viviendas cercanas a las escuelas, muchos de ellos en condiciones precarias de habitabilidad.

\section{Aspectos metodológicos}

El estudio del que surgen los resultados que se analizan en el próximo apartado utilizó una metodología de carácter cualitativo y recurrió a fuentes primarias y secundarias ${ }^{8}$ de investigación. Uno de sus objetivos

6 La medición de la pobreza multidimensional en Chile considera variables educativas (asistencia y rezago escolar, escolaridad), de salud (malnutrición, adscripción a sistema de salud y atención de salud), trabajo y seguridad social (ocupación, seguridad social y jubilaciones), vivienda y entorno (habitabilidad, servicios básicos y entorno), y redes y cohesión social (apoyo y participación social, trato igualitario y seguridad) (Ministerio de Desarrollo Social, 2016).

7 En una escala en la que el $100 \%$ representa la máxima vulnerabilidad.

8 Además de datos cuantitativos de bases de datos (encuesta Casen 2015 y base de datos de matrículas del Ministerio de Educación de 2016), se analizaron los planes 
específicos $^{9}$, que es aquel del que surgió este artículo en particular, fue conocer y sistematizar los principales enunciados que estructuran las tramas narrativas de profesores, asistentes de la educación y directivos, así como de los encargados de los departamentos de educación municipal, con respecto a los desafíos que la multiculturalidad, entendida en sentido descriptivo ${ }^{10}$, representa para su práctica pedagógica y para la dinámica de su comunidad educativa en general. Este propósito se apoyó en el supuesto según el cual esas narrativas se materializan en prácticas pedagógicas, y, por lo tanto, podrían aportar elementos para orientar el proceso de autorreflexión sobre la práctica del docente que se procuraba mediante el estudio, con el objetivo de avanzar hacia una escuela intercultural, en su vertiente crítica. Es decir, entendíamos que el modo en que estos actores de las comunidades educativas visualizaban y concebían esa multiculturalidad determinaba en buena medida las acciones e inacciones frente a ella en el proceso de enseñanza-aprendizaje, en articulación con otros factores, como las normas institucionales, los recursos disponibles, entre otros. Es por eso que resulta relevante explorar los enunciados que se construyen en estas tramas narrativas en torno a este proceso social.

Por tramas narrativas entendemos, según la propuesta teórico-metodológica de Leonor Arfuch (2002; 2016),

los relatos resultantes de procesos de construcción de significaciones en torno a determinados referentes, dando sentido a lo que sucede en el mundo social y en la propia vida [...], y que constituyen la apropiación personal de los discursos sociales a partir de la enunciación (Stang, 2018, p. 90).

El enunciado, en tanto, se entiende como "la modalidad de existencia de un conjunto de signos [...] que le posibilita ser algo más que un simple

anuales de desarrollo educativo (Padem) municipales y los proyectos educativos institucionales (PEI) de las escuelas. Se revisaron también más de 100 documentos (artículos científicos, publicaciones de libros y páginas web) buscando experiencias sobre educación intercultural de los siguientes países: Chile, Argentina, Colombia, Perú, México, Brasil, Bolivia, Costa Rica, Ecuador, Paraguay, Venezuela, España, Reino Unido, Francia, Bélgica, Alemania, Austria, Estados Unidos y Canadá.

9 El objetivo general, en tanto, apuntaba a elaborar lineamientos de una propuesta de política y de escuela intercultural que atienda al contexto multicultural y pluriétnico, y que tenga como eje central la incorporación de la capacidad reflexiva sobre la práctica, transformando las jerarquías basadas en la etnia, la nacionalidad, la clase y el género, para procurar un sistema educacional democrático y participativo en el que la diversidad constituya un valor central.

10 Es decir, como hecho de la realidad, que alude a la presencia de varias culturas en un mismo espacio social. 
conjunto de marcas materiales: referirse a objetos y a sujetos, entrar en relación con otras formulaciones y ser repetible" (Castro, 2004, s. p.). Es, por lo tanto,

mucho más que una oración, una frase, o una cita referida a un tópico determinado; es la irrupción histórica — material y contextualizada - del discurso social a partir de un acto de enunciación que permite coagular en la superficie textual ciertas densidades significantes construidas socialmente en ese tiempo y espacio que determinan las coordenadas que permiten la emergencia de ese sujeto de la enunciación (Stang, 2018, pp. 87-88).

El corpus del que emerge la propuesta analítica de este artículo está compuesto por las transcripciones de las entrevistas semiestructuradas a actores clave de las comunidades educativas en las que se realizó el trabajo de campo: directores(as), jefes(as) de las unidades técnico-pedagógicas (UTP), encargados de convivencia, y directivos de los departamentos de educación municipal de las comunas a las que pertenecen las escuelas (19 entrevistas en total). Además, lo componen los registros etnográficos surgidos de las observaciones de talleres realizados con docentes y asistentes de la educación de los mismos establecimientos.

El uso de este último instrumento metodológico responde a la consideración de elementos de investigación-acción participativa (IAP) en el diseño de la estrategia de levantamiento de información. Estos talleres con docentes y asistentes de la educación tenían por objetivo lograr un diagnóstico de los desafíos que implica la presencia de estudiantes migrantes para su labor pedagógica, conocer las prácticas que los profesores están implementando para abordarlos y generar una reflexión en torno a ellas. Este punto en particular, es decir, la generación de una instancia de reflexión sobre la propia práctica, era fundamental para los propósitos del estudio, que, en términos generales, apuntaba a generar "desde abajo" lineamientos para abordar la presencia de estudiantes migrantes desde la práctica pedagógica. Es justamente por esta relevancia de la autorreflexión de los profesores y asistentes de las escuelas que analizar las tramas narrativas que construyen en torno a este tema (el propósito específico de este artículo) resulta necesario, y podría representar un aporte, en la medida en que son actores fundamentales a la hora de materializar cualquier enfoque que implique una transformación en la escuela.

Se realizaron entonces dos talleres por colegio (excepto en la escuela 3, por modificación de su calendario académico), con el objetivo de contar con un diagnóstico participativo de los desafíos pedagógicos que representaba la migración e identificar prácticas orientadas a resolverlos. En el 
segundo taller, efectuado en promedio tres semanas después del primero, se buscó reflexionar en torno a la implementación de las prácticas propuestas por los participantes en la primera instancia, a partir de la observación sistemática que se comprometían a realizar. De este modo, se siguió el ciclo de diagnóstico-acción-observación-reflexión que caracteriza a la IAP.

En la tabla 2 se observan las entrevistas realizadas en cada escuela y la cantidad de docentes y asistentes que participaron en los talleres.

Tabla 2

Entrevistas y talleres realizados en las escuelas de la muestra, 2017

\begin{tabular}{|c|c|c|c|c|}
\hline & DAEM $^{a}$ & Directivos de colegios & Taller $1^{\text {b }}$ & Taller $2^{b}$ \\
\hline Independencia & \multicolumn{4}{|l|}{1 Miembro directivo } \\
\hline Escuela 1 & & $\begin{array}{l}\text { Director(a), jefe(a) de UTP y } \\
\text { encargado(a) de convivencia (3) }\end{array}$ & 23 & 26 \\
\hline Escuela 2 & & Director(a) e inspector(a) (2) & 9 & 10 \\
\hline Recoleta & \multicolumn{4}{|l|}{2 Miembros directivos } \\
\hline Escuela 3 & & $\begin{array}{l}\text { Director(a), jefe(a) de UTP y } \\
\text { encargado(a) de convivencia (3) }\end{array}$ & \multicolumn{2}{|c|}{51} \\
\hline Escuela 4 & & $\begin{array}{l}\text { Director(a), jefe(a) de UTP y } \\
\text { encargado(a) de convivencia (3) }\end{array}$ & 20 & 8 \\
\hline Quilicura & \multicolumn{4}{|l|}{1 Miembro directivo } \\
\hline Escuela 5 & & $\begin{array}{l}\text { Director(a) y encargado(a) } \\
\text { de convivencia ( } 2 \text { ) }\end{array}$ & 23 & 21 \\
\hline Santiago & 2 Miembros directivos $^{c}$ & & & \\
\hline
\end{tabular}

a Departamento de Administración de Educación Municipal.

${ }^{b}$ La cifra que aparece en esta columna corresponde a la cantidad de profesores y asistentes de la educación que participaron de ese taller.

c Inicialmente se había contemplado trabajar también en una escuela de la comuna de Santiago, pero, dado que las gestiones a través de la Dirección de Educación municipal no fueron fructíferas, ese caso debió descartarse, decisión que no incidió en la saturación de los resultados. De todos modos, dado que se entrevistó a dos funcionarios técnicos del organismo municipal, se ha considerado su trascripción en el análisis del corpus.

Fuente: elaboración propia

El procedimiento de codificación utilizado en el corpus, realizado mediante el programa Atlas.ti, fue de tipo inductivo, guiado por los objetivos del estudio. En términos de la teoría fundamentada, se trató de una codificación guiada por los datos (Gibbs, 2012), que operó solamente hasta el nivel de codificación abierta. A partir de una primera codificación emergente, la mayor parte realizada considerando las categorías nativas encontradas, se procedió a agrupar por familias de códigos, a saber: 1) Contexto de la escuela, 2) Dificultades con incidencia directa en el proceso educativo, 3) Dificultades con incidencia indirecta en el proceso educativo, 4) Enfoques 
y percepciones sobre el abordaje de la migración en la escuela, 5) Percepciones y actitudes frente a los migrantes y 6) Prácticas escolares. El análisis que se presenta en este artículo se concentró en la familia de códigos 4.

La validación del procedimiento de codificación residió principalmente en el nivel de aglomeración de citas en los códigos emergentes, que fue significativa, y en ciertos casos por la originalidad del hallazgo. Es importante mencionar que hubo una instancia preliminar de análisis y sistematización, específicamente de las observaciones realizadas en los talleres, pues parte del segundo taller suponía exponer a los profesores y asistentes de la educación los hallazgos que se habían realizado a partir del primer encuentro en todas las escuelas, que fueron notablemente coincidentes. Esta instancia supuso una fase intermedia de sistematización, a partir de una lectura reflexiva que permitió observar estas coincidencias generales en las tres comunas. También constituyó una instancia de validación consensual de estos hallazgos con los profesores y asistentes de la educación, en consonancia con la decisión de incorporar elementos de la IAP al trabajo de campo.

Por último, en relación con las limitaciones del estudio, es necesario mencionar que el trabajo en terreno enfrentó diversos problemas que dificultaron el acceso a los establecimientos educacionales y a los docentes y asistentes de la educación en el momento de realizar los talleres. Estos problemas estaban vinculados con el escaso tiempo con que cuentan las escuelas, en general, y los profesores y asistentes de la educación, en particular, para participar en las actividades contempladas en proyectos de investigación; el cansancio producido por la sobreintervención de la que están siendo objeto por parte de diversos equipos de investigación, organizaciones sociales, estudiantes en práctica o tesistas, entre otros, y la escasa reciprocidad que reciben de estas intervenciones, una situación que el equipo procuró subsanar a partir de la realización de un seminario de difusión de resultados, además de apoyo profesional directo a uno de los establecimientos.

\section{Resultados: enunciados en torno a los desafíos que impone la migración a las escuelas}

La sistematización y el análisis del corpus conformado a través del trabajo de campo, descrito en el apartado previo, mostró un uso bastante extendido de los términos multiculturalidad e interculturalidad, ligado al contexto migratorio. En este contexto de crecimiento significativo de la matrícula de alumnos migrantes internacionales, en algunas escuelas públicas de ciertas comunas del país, se han ido instalando ambas ideas en diversos 
actores de estas comunidades escolares, en un proceso relacionado con varios factores que actúan tanto desde arriba como desde abajo, en una compleja imbricación.

Entre estos factores se puede mencionar, por ejemplo, la progresiva instalación de estas nociones, de modo bastante difuso, desde algunos de los organismos municipales encargados de administrar estas escuelas hasta el momento ${ }^{11}$. Esto ha ocurrido como una forma de responder a la demanda implícita de un enfoque de política pública para abordar esta realidad en cierto modo novedosa ${ }^{12}$, ante la ausencia de una política migratoria desde el nivel central del Estado. También ha incidido en el creciente uso de estos términos la presencia de organizaciones de la sociedad civil que realizan intervenciones en algunos de estos establecimientos, y que han ido instalando estos conceptos en diversas instancias; la realización de investigaciones académicas desde marcos teóricos que consideran estas nociones y que toman a estas escuelas como escenario, entre otros elementos. A estos factores hay que agregar que los diversos actores de las escuelas se sienten interpelados por este contexto escolar relativamente nuevo y genuinamente llamados a buscar herramientas diferentes a las que ofrece la educación tradicional.

Pero en ausencia del abordaje de estos temas en la formación del profesorado o en orientaciones desde el Ministerio de Educación, al menos hasta el momento de desarrollar el trabajo de campo ${ }^{13}$, se advierte, como consecuencia, una apropiación difusa de estos conceptos, como los propios actores señalan:

Es una realidad en donde los profesores han tratado de entregar una respuesta satisfactoria con sus propias herramientas, considerando que no tienen formación específica en la materia. Y nos encontramos con un ministerio que no entrega ninguna orientación sobre la materia. Sin dejar de considerar que todavía incluso tenemos situaciones poco claras respecto

11 En 2017 comenzó a implementarse una reforma educacional a nivel nacional, que en el mediano plazo pondrá en marcha los así llamados Servicios Locales de Educación (SLE) y eliminará la administración municipal de una parte de las escuelas del sistema educativo chileno.

12 Decimos "en cierto modo" porque la diversidad cultural en la sociedad chilena es un hecho previo a esta llegada reciente de migrantes internacionales.

13 Tiempo después de la realización de este estudio, el Ministerio de Educación publicó dos documentos con intenciones orientativas en esta materia (Ministerio de Educación, s. f., 2017), aunque no se ha podido verificar su difusión efectiva en los establecimientos educativos. De todos modos, esto no contradice la afirmación sobre la ausencia de un enfoque general y claro respecto a cómo debiera abordarse el tema desde la política educativa. 
de la materia de interculturalidad versus la multiculturalidad ${ }^{14}$ (entrevista a miembro directivo del DAEM Independencia).

En este marco, uno de los enunciados en torno al cual se advierte la conformación de un punto noda $1^{15}$ en las tramas narrativas de los actores que participaron en el estudio es el que asocia los desafíos de la multiculturalidad, derivada de la presencia de alumnado migrante, con la idea de inclusión. Esta idea está bastante permeada por la puesta en marcha de la Ley de Inclusión Escolar (20845), que se promulgó en 2015 y entró en vigencia en 2017. El argumento, en términos generales, es que todos los estudiantes deben ser incluidos en las escuelas, en consecuencia, también deben ser incluidos los estudiantes migrantes:

Yo creo que hay un eje que ha dado la política comunal y la ley de convivencia: la ley de inclusión, y es que aquí el tema migrantes es un punto más dentro de las otras integraciones, no es un tema. El respeto es porque son personas. Yo creo que hemos ido instalando esta mirada más inclusiva. El valor es la diversidad en el fondo, porque cuando ha habido dificultades se han hablado y finalmente son problemáticas de niños que se deben resolver con ellos. Hacerlos reflexionar, esa ha sido la lógica que hemos tenido, y en la multiculturalidad caben todos los temas (entrevista a director[a] de la escuela 2, Independencia).

La discusión sobre la Ley de Inclusión Escolar se instaló en la agenda pública chilena con mucha fuerza, como una reivindicación del derecho (y como contrapartida, de la obligación del Estado) de acceder de modo igualitario a la educación, con el trasfondo de un sistema educativo nacional muy segregado en términos socioeconómicos ${ }^{16}$. La fuerza de esta instalación en la opinión pública ha permeado el modo de pensar muchas de las problemáticas actuales del sistema de educación chileno y ha alcanzado, por lo tanto, a la migración. Esta permeabilidad se evidencia en la profusión

14 Todos los énfasis en las citas son propios.

15 Entendemos por punto nodal, siguiendo la formulación de Laclau \& Mouffe (1987), los "puntos discursivos privilegiados" (pp. 128-129) en la fijación parcial de sentido que se va realizando a partir de los discursos.

16 Esta ley constituye una respuesta de política pública a la profunda desigualdad que caracteriza al sistema educativo chileno (y a la sociedad chilena en general), y que movimientos sociales como la llamada revolución pingüina pusieron en agenda en los últimos años (para mayor información sobre este movimiento, véase Consejo Latinoamericano de Ciencias Sociales, 2012). Esta desigualdad educativa se relaciona centralmente con la facultad de los colegios particulares subvencionados y particulares pagados para cobrar a sus estudiantes y, además, para seleccionarlos para el ingreso, lo que se acaba con la implementación de la ley de inclusión. 
de alusiones a esta idea por parte de los actores, en el momento de dar cuenta de la forma en que han estado respondiendo a los desafíos que ha supuesto a su práctica pedagógica la presencia de estudiantes migrantes en sus escuelas:

Nosotros somos un colegio que está abierto, que recibe a todos los estudiantes, un colegio donde la inclusión es el centro de ello, por lo tanto, no es un colegio donde uno pudiera de alguna manera el profesor decir: "Este niño, este alumno no es para mí, no estoy acostumbrado a estos alumnos", porque el colegio tiene un sello ${ }^{17}$ que lo distingue (entrevista a director[a] de la escuela 5, Quilicura).

El sentido de inclusión que prima en los enunciados es el que se refiere a la incorporación de todos, sin discriminación, a la escuela en general, y el proceso de enseñanza-aprendizaje en particular, tanto en su sentido afirmativo como en el negativo, es decir, lo que se debe evitar hacer, asociado directamente con la fuerza de la norma (la ley de inclusión):

Otro profesor dice que no pueden hacer eso [solicitar al municipio que exija a los estudiantes haitianos tomar un curso de español antes de ingresar a la escuela], porque ellos han decidido ser una escuela inclusiva, y varios se adhieren a esa posición (observación en el taller 1, escuela 5, Quilicura).

— ¿Cuál es la visión que el equipo directivo de la escuela intenta transmitir a toda la comunidad educativa sobre los niños migrantes?

- Por ahora, como no hay algo específico, porque si hay algo que se ha integrado es la ley de inclusión. Creo que en Chile esto sí está bien en realidad, no creo que lo sepan plenamente, pero sí saben que les puede caer la mano si hay discriminación. Aunque puede haber alguna ocasión en que acontezca la discriminación, si bien puede estar el sentimiento, pero no la expresión viva y constante (entrevista a director[a] de la escuela 4, Recoleta).

Por la visibilidad que le ha conferido la discusión, aprobación e implementación de la ley, la idea de inclusión actúa como punto nodal que permite su articulación con varias cadenas de sentido. Una de ellas es la que la

17 Con la idea de sellos educativos, el Ministerio de Educación de Chile se refiere a "los aprendizajes que [las escuelas] consideran esenciales para el desarrollo del proceso educativo de sus estudiantes. Estos 'aprendizajes esenciales' [...] definen a la institución escolar y [...] la singularizan en relación con otras" (Ministerio de Educación, 2015, p. 12). Estos sellos son definidos periódicamente por las propias escuelas. 
vincula a la multiculturalidad e interculturalidad, la mayor parte de las veces de manera bastante inespecífica:

Es la propuesta, cómo te enseño de tal manera que el niño aprenda y le entusiasme aprender y que sea inclusivo, pero además ver la oportunidad de ese contenido, que le agregamos la mirada más intercultural, multicultural, frente a un fenómeno real. Por ejemplo, en sexto básico estaban viendo los riesgos naturales. La idea es [...] ampliar la mirada y ver más allá desde lo pedagógico, es bueno que ellos vean y hagan comparaciones de algunos fenómenos que ocurren en muchos lugares y se repiten también culturalmente (entrevista a director[a] de la escuela 2, Independencia).

Otra de las cadenas de sentido que se articula al punto nodal de la inclusión es aquella que construye el desafío que representa la presencia de estudiantes migrantes en las escuelas como un tema de buena convivencia, que debe ser abordado a partir de valores y actitudes como el respeto mutuo, la comprensión y la empatía:

Yo te hablo de lo que es mi trabajo que es la convivencia, y mejorando el respeto por el otro se va mejorando en otros aspectos, por añadidura, para que con el tiempo se vaya dando la inclusión. No te digo que lo vamos a resolver este año, porque hay harto trabajo por hacer a nivel comunal y ministerial para que la interculturalidad surta efecto en los niños y también en los profesores, para no mirar con cierto recelo a ningún niño, sino acogerlo, acompañarlo, aconsejarlo (entrevista a encargado[a] de convivencia de la escuela 5, Quilicura).

Estos enunciados están muy vinculados con uno de los dos grandes enfoques que Jiménez, Aguilera, Valdés \& Hernández (2017) detectaron en el abordaje que realizan documentos estatales vinculados a la relación entre migración y escuela en Chile, producidos entre 2000 y 2016, que constituyen una forma de cristalización del pensamiento de Estado sobre este asunto. Los autores encontraron un grupo de documentos recientes con "un enfoque más integral orientado al desarrollo de la interculturalidad", aunque ciertamente acotado: "La interculturalidad está circunscrita al ámbito de la convivencia y, por tanto, es una perspectiva parcial de educación intercultural" (Jiménez et al., 2017, p. 111). Estas coincidencias entre los documentos públicos y los discursos de estos actores que son parte de instituciones públicas no parecen casuales, aunque establecer sus relaciones y formas de incidencia demandaría una investigación específica.

El otro gran enfoque que reconocen estos autores en su exhaustiva revisión de documentos estatales es el enfoque de derechos, basado en la idea 
de no discriminación en el espacio escolar, y fundado en el principio de la igualdad de oportunidades. De manera coincidente, en nuestro trabajo encontramos una condensación de enunciados en torno a este eje argumental:

Lo que hemos hecho ha sido no centrar el tema en la interculturalidad sino en el tema de los estudiantes migrantes desde el enfoque de derechos, entonces aparece la condición de intercultural o de migrante o de la condición de género, es decir, de lo que se te ocurra. Esto yo te podría decir que lo hemos subrayado mucho, que la mirada parte de la condición de representante del Estado como garante de derecho y desde ahí el reconocimiento de cada una de las particularidades de nuestros residentes (entrevista a miembro directivo del DAEM, Independencia).

- ¿Desde la escuela se han ido desarrollando algunas acciones específicas respecto de los niños migrantes [...], alguna práctica o medida que se haya realizado?

- No específicamente, más bien ha sido a nivel institucional desde la convivencia, ahí hemos avanzado desde el enfoque de derechos, y además un proceso de nivelación de lectoescritura (entrevista a director[a] de la escuela 2, Independencia).

Esta mirada en torno al enfoque de derechos es acompañada en varios actores por la idea de que los alumnos extranjeros no requieren un abordaje específico en el proceso de enseñanza-aprendizaje ni en su incorporación a la escuela. En la medida en que "todos los niños son iguales" (en derechos), no parecería lógico, en esta argumentación, establecer abordajes diferenciados o específicos:

Yo no voy a capacitar a un profesor en migración. No creo que sea relevante, sí creo que debería albergar una emocionalidad que le permita ser capaz de convivir con el otro en su individualidad y diferencia. Lo que estoy diciendo es que no estamos preocupados de que nuestros profesores sean capaces de hacerle una clase a nuestros niños migrantes, estamos preocupados que nuestros profesores sostengan la realidad que enfrentan y le hagan clases a todos los niños (entrevista a miembro directivo del DAEM, Recoleta).

Yo creo que tú no tienes que hacer cosas distintas, o sea, cuando tú hablas de inclusión o de integración no es que tú hagas notar la diferencia, al contrario. Tú lo que tienes que hacer es integrarlos y que ellos sean uno más del establecimiento, entonces, hacer cosas distintas o especiales no me parece (entrevista a director[a] de la escuela 1, Independencia). 
Otro de los enunciados construidos en estas tramas narrativas en torno a los desafíos que supone la migración en las escuelas es la necesidad de adaptación de los alumnos extranjeros, ya sea de un modo imperativo o en una variante positiva, como una valoración de su capacidad de adaptación:

A partir de esto surge una discusión en torno a la observación de una de ellas [las docentes] respecto de que "Ellos se tienen que adecuar al país al que llegan. Cuando un extranjero llega a los Estados Unidos tiene que saber inglés para poder estar" (observación en el taller 1 en la escuela 5, Quilicura).

Quizá por un tema de antropología cultural, ellos desarrollan habilidades que al estar en un país extraño opera la capacidad de adaptación, de escuchar, de sumergirse en la cultura en la que están, tener aceptación del otro (entrevista a miembro directivo del DAEM, Recoleta).

Esta mirada sobre los desafíos ante la multiculturalidad del aula, desde la realidad migratoria, revela un lugar de enunciación normativo, según el cual se debiese tender hacia un horizonte homogeneizador:

Cuentan el caso de un niño haitiano, "el Pierre" [...], que hubo que "socializarlo" ("que sea más humano"), porque nunca había ido a la escuela, llegó en primero básico. Cuentan que costó mucho porque caminaba sobre las mesas, no se quedaba sentado porque no estaba acostumbrado, "nunca había visto un cuaderno", así que le extrañaba mucho, además no hablaba español (observación en el taller 1 en la escuela 1, Independencia).

Sí creo que claramente van a presentar más dificultades [los estudiantes migrantes], porque hay un sentido común que es característico de la zona donde uno vive, del país donde uno vive, y sobre todo de este diario vivir, porque efectivamente todo esto permite reaccionar de manera adecuada o de maneras que correspondan a la norma, y al llegar una persona extranjera a ocupar un espacio en ese sentido común donde pueden haber rasgos generales que intenten modificar ese sentido común, pueden pasar varios años para que se logre homogenizar (entrevista a jefe[a] de la UTP de la escuela 1, Independencia).

Desde una posición diferente, aparece en el corpus un enunciado que liga la llegada de estudiantes migrantes a las escuelas con la idea de una diversidad que viene a enriquecer el aula, en particular, y la escuela, en general, y que, por lo tanto, debe ser considerada como un aporte y una oportunidad:

Señalan que los niños migrantes traen vivencias de otros países, un vocabulario distinto, y esto enriquece, permite compartir viéndose un igual [...]. 
La presencia de niños migrantes amplía la cosmovisión de la escuela, por ejemplo, con las comidas que los niños traen para su colación, que implica una mayor variedad (arepas, plátanos fritos, etc.) (observación en el taller 1 en la escuela 2, Independencia).

— ¿Qué reflexiones te genera a ti el término de interculturalidad?, ¿en qué piensas?

- Yo creo que lo asocio con enriquecimiento, creo que la mezcla de variadas culturas enriquece a una población, de todos hay que aprender, de todo hay que aprender. Todos podemos aprender del otro (entrevista a director[a] de la escuela 1, Independencia).

También apareció en algunos actores una mirada de estos procesos que están ocurriendo en las escuelas desde una concepción de la interculturalidad como un encuentro de culturas que deben aceptarse entre sí, respetarse, y que en ese proceso se "ensamblan" o "se hacen una", aunque no fue uno de los enunciados más densos de estas tramas narrativas:

Para mí, [la interculturalidad] es el complemento o la fusión de distintas culturas, es la convivencia y la relación entre las culturas de manera conjunta. De esta mezcla de la fusión y el ensamble cultural de enseñanza y aprendizaje de las distintas culturas, de lograr comprender, aceptar la cultura distinta (entrevista a miembro directiva del DAEM, Quilicura).

Uno de los sellos que estamos trabajando con los profesores es la multiculturalidad, y que debiera transformarse muy gradualmente en la interculturalidad, porque no es lo mismo. Y ese paso es mucho más complejo aún, porque la idea es que dos culturas hacen una [...]. Multiculturalidad no habla que yo tengo alumnos peruanos, colombianos, haitianos, chilenos y otros hacia el interior de la sala de clases, pero se distinguen unos de otros, en algún momento tiene que haber un cruce, y nosotros en ese momento debemos estar atentos cuando se dé. Entonces, cuando un chileno comience a hablar medio colombiano y un colombiano medio chileno, eso va a ser interesante (entrevista a director[a] de la escuela 3, Recoleta).

Por último, emergió del corpus la asociación de la interculturalidad con una práctica pedagógica transformadora, en la medida en que permita avanzar desde la multiculturalidad a la interculturalidad:

- ¿Te hace sentido avanzar en la incorporación de una perspectiva intercultural en la escuela?, ¿qué reflexión te genera ese término de interculturalidad? 
—Sí, académicamente no lo podría definir, he leído mucho sobre el tema y aún no tengo una definición única y clara. Mi sentido es que como práctica pedagógica tengo que asumir mi realidad y esta es la multiculturalidad. Yo estoy aquí para que los niños aprendan y mi aprendizaje debe ser transformador, es decir, yo quiero que el niño transforme a la sociedad, quizá suene utópico, pero eso es lo que yo hago aquí y voy a seguir haciendo. Entonces, acepto la multiculturalidad, la valoro. Entonces tengo el deber ético de atacarla (eso en el buen sentido) para conseguir los mejores aprendizajes transformadores, y la única forma es entendiendo que tengo que avanzar a la interculturalidad a través del rescate de la cultura de cada uno de ellos, incluida la de los chilenos, los chilenos indígenas o de pueblos originarios. Rescatar además las experiencias y visión de los apoderados ${ }^{18}$ de todos los países, es decir, rescatar su cultura y no imponer, de tal manera de construir aprendizajes en común rescatando su forma de aprender (entrevista a jefe[a] de la UTP de la escuela 3, Recoleta).

Aunque se trata de la voz de un actor específico, es importante relevar la emergencia de este enunciado, en su especificidad, en la medida en que permite visibilizar formas de resistencia a otros enunciados más instituidos.

\section{Discusión: dos tipos de discurso y una apropiación acrítica de la interculturalidad}

El análisis de los principales enunciados identificados en las tramas narrativas de los actores de las comunidades educativas con las que se trabajó en el estudio pueden agruparse, en términos generales, en dos tipos de discursos: por una parte, uno que llamaremos asimilacionista y universalizador, que recurriendo a argumentos como la necesidad de adaptación, el enfoque de derechos o la demanda de inclusión tiene como trasfondo una mirada homogeneizante de la diversidad cultural asociada a la presencia de estudiantes migrantes. Por la otra, uno que denominaremos el discurso de la tolerancia y la hibridez, que enfatiza el enriquecimiento de la diversidad que esta presencia implica, la necesidad del respeto y la tolerancia por estas diferencias o la valoración de una eventual hibridez cultural que se estaría produciendo. A partir del análisis que se presenta en este apartado, argumentaremos que en ambos casos, desde la perspectiva de la interculturalidad crítica, se trata de discursos que se inscriben en una mirada funcional de la interculturalidad, ya que no cuestionan la desigualdad estructural que

18 En el sistema educativo chileno, se entiende por apoderado(a) a la madre, el padre, familiar o adulto responsable del estudiante ante el establecimiento educativo. 
subyace a las jerarquías culturales y sociopolíticas que se juegan en la cotidianeidad de aulas en las que confluyen estudiantes nacionales y migrantes.

Estos discursos, como hemos señalado, representan modos de concebir el proceso social en cuestión, y esas concepciones se materializan en prácticas pedagógicas, entendidas como acciones, pero también como inacciones. En este último sentido hemos observado, por ejemplo, en este trabajo de campo y en otros en los que hemos participado, situaciones de invisibilización y negación de actitudes y conductas racistas contra los estudiantes extranjeros (Riedemann \& Stefoni, 2015; Stefoni, Stang \& Riedemann, 2016). Cabría preguntarse, entonces, si estas formas de entender y abordar el proceso social no habilitan de algún modo la reproducción de estas situaciones. No es el propósito de este artículo, ni del estudio del que surge, establecer estas relaciones causales, sin embargo, conocer los enunciados construidos en torno a la presencia de estudiantes migrantes en las escuelas es un primer paso relevante para reflexionar sobre la manera en que pueden estar en la base de este tipo de situaciones y para vislumbrar vías de acción que apunten a transformarlas. Para ello, avanzaremos en algunas discusiones en torno a los enunciados sobre los que se construyen estos discursos.

Dentro del primer tipo de discurso que distinguimos (asimilacionista y universalizador), aparece con fuerza el enunciado de la inclusión, principalmente acotado al campo educativo, es decir, a la noción de inclusión educativa (Armijo-Cabrera, 2018). En ese sentido específico, la inclusión es definida como "un conjunto de procesos orientados a aumentar la participación de los estudiantes en la cultura, los currículos y las comunidades de las escuelas" (Blanco, 2006, citado en Booth \& Ainscow, 2004, s. p.). Como se desprende de la lectura de esta definición, considerada un referente en el campo de la educación, la inclusión implica hacer parte del sistema educativo a alguien que está por fuera de él, pero sin poner en cuestión ese adentro, es decir, dándolo por sentado y, por ende, legitimándolo como deber ser. Por lo mismo, esa inclusión acarrea de suyo una forma de homogeneización y asimilación, que contradice los supuestos de la interculturalidad.

Además de su potencial homogeneizador y asimilacionista, otro riesgo de este tipo de narrativas, y sobre todo de su institucionalización, es que generen una normalidad integradora de la diversidad cultural existente (Sinisi, 1999) que termine enmascarando y naturalizando procesos de discriminación y desigualdad, como efectivamente se ha estado observando en escuelas de la Región Metropolitana con presencia de estudiantes migrantes (por ejemplo, Riedemann \& Stefoni, 2015; Stefoni et al., 2016; Tijoux, 2013a; 2013b). 
El enunciado que liga los desafíos de la multiculturalidad generada por la llegada de estudiantes migrantes con el enfoque de derechos y, a partir de él, con una distinción entre igualdad y diferencia, también forma parte de este primer tipo de discurso. El argumento general que está en su base es que esta copresencia de "culturas" diferentes o esta existencia de diferencias culturales es casi un epifenómeno que no debe distraernos del hecho de que todos los niños son iguales (en derechos). Se trata de un argumento que, por lo tanto, superpone planos de análisis distintos: la diferencia cultural es diluida por un supuesto sustrato anterior, la humanidad, que no es sino una construcción cultural específica. De ese modo, la multi o la interculturalidad terminan ligadas a una garantía del derecho a la educación que debe asegurarse por la calidad de ser humano, obviando las diferencias de poder que se juegan en la materialización de ese derecho. En estas diferencias, las dimensiones de extranjeridad y nacionalidad se intersecan con las de clase, género, etnia, "raza", generación, entre otras, remitiendo a los niños migrantes, en general, a las escalas más bajas de la jerarquización social que se produce a partir de esas intersecciones. Es decir, a partir de esa explicación universalizadora, se terminan invisibilizando las desigualdades que se construyen a través de esas diferencias o que están en su base.

Estos enunciados ponen en escena una discusión ya instalada hace tiempo en el escenario académico y sociopolítico global: aquella que surge de la tensión entre el derecho a la igualdad y el derecho a la diferencia. Se trata de un debate que ha tomado varias formas en el espacio académico y también en la arena política. Boaventura de Sousa Santos (2002), por ejemplo, ha sostenido al respecto que "las personas tienen el derecho a ser iguales cuando la diferencia las haga inferiores, pero también tienen el derecho a ser diferentes cuando la igualdad ponga en peligro la identidad" (p. 81), es decir, la igualdad no debe ni puede demandar una homogenización identitaria. Ferrajoli (1999), por su parte, propone que ambos derechos no pueden oponerse, porque están en niveles distintos: el derecho a la diferencia está supeditado al derecho a la igualdad, es un requisito para que la igualdad se logre. Desde nuestro punto de vista, que no es jurídico, no se trata ni de derechos opuestos ni jerárquicamente diferentes, sino de derechos complementarios: ambos deben cumplirse para que cada uno de ellos esté garantizado, pues si en el afán de garantizar el derecho a la igualdad se vulnera el derecho a la diferencia, aquel no puede darse por garantizado, en la medida en que no hay igualdad posible si se desconocieron esas diferencias. 
El enunciado de la adaptación también es parte de este discurso asimilacionista y universalizador. Se vincula a narrativas enmarcadas en miradas alineadas con la monoculturalidad del sistema educativo nacional, que en el fondo implican una deslegitimación, implícita o explícita, de otras matrices culturales, y su consecuente jerarquización. Aunque este enunciado es en apariencia contradictorio con los dos previos (el de la inclusión y el basado en el enfoque de derechos), los tres apuntan a las mismas implicancias: la deslegitimación del otro y, en consecuencia, un imperativo de homogenización. La inclusión, como dijimos, porque pretende hacer parte de un sistema cuya legitimidad se da por descontada a aquel que se construye como una forma de alteridad; el enfoque (occidental) de derechos, porque su universalismo también se sustenta en un horizonte monocultural y, además, en su mirada individualista, tampoco problematiza las condiciones estructurales de la desigualdad.

En el segundo tipo de discurso que distinguimos, el de la tolerancia y la hibridez, se encuentra el enunciado de la migración como aporte a la diversidad cultural. Es relevante detenerse en el hecho de que, a pesar de la valoración positiva que revela esta trama narrativa, y de las buenas intenciones que pueden sustentarla, estos argumentos con respecto al aporte de las migraciones a la sociedad receptora, en general, y a la comunidad educativa, en particular, tienden a conducir los abordajes de la migración hacia una lógica binaria costo-beneficio, que puede resultar un arma de doble filo: al evaluar la migración como un aporte, más que considerarla una realidad global o el ejercicio de un derecho, se corre el riesgo de que, por situaciones fortuitas y arbitrarias, esta evaluación positiva cambie y también se pueda tornar en lo contrario. Por ejemplo, hemos encontrado en el trabajo de campo testimonios de actores educativos para los que la presencia de alumnos migrantes se asocia a una situación problemática por el hecho de que algunos profesores consideran que ocasionalmente retrasan el desarrollo habitual de las asignaturas y materias, aparentemente porque en sus países de origen el currículum era diferente; porque, por diversas razones, no pudieron asistir a clases por períodos prolongados, o incluso porque hablan otra lengua. Este "desnivel" que los profesores señalan es sindicado como responsable de la disminución en los puntajes de pruebas estandarizadas en los establecimientos donde se desempeñan, lo cual tiene múltiples consecuencias negativas en la evaluación y la valoración de estas escuelas por parte de los sistemas de medición oficiales del Ministerio de Educación.

Los enunciados relativos al encuentro de culturas y el ensamblaje, también componentes de este segundo tipo de discurso, revelan una mirada próxima a definiciones de la interculturalidad entendida como "una 
situación, proceso o proyecto que se produce en el espacio 'entre' distintas formas de producción cultural" (Novaro, 2006, p. 2). Sin embargo, las ideas de ensamblaje o unión a las que se alude tienen como telón de fondo ciertas representaciones en torno a una comunión armónica de culturas mucho más cercanas a lo que Tubino (2005) ha definido como la vertiente funcional de la interculturalidad, que "busca promover el diálogo y la tolerancia sin tocar las causas de la asimetría social y cultural hoy vigentes" (Tubino, 2005, p. 2). Según Catherine Walsh (2011), esta perspectiva de la interculturalidad "se enraíza en el reconocimiento por los Estados de la diversidad con pretensión de resolver el problema de las 'minorías', con metas hacia su inclusión al interior de la sociedad nacional y la estructura social establecida" (p. 101).

Estas reflexiones con respecto a los enunciados a partir de los cuales se construyen los dos tipos de discurso identificados (el asimilacionista y universalizador, y el de la tolerancia y la hibridez) permiten observar, entonces, que ambos terminan siendo funcionales a una institucionalización acrítica del concepto de interculturalidad, en la medida en que tienden a invisibilizar la desigualdad que subyace al encuentro de culturas hegemónicas y subalternizadas, y los procesos sociohistóricos que condujeron a esa construcción jerárquica. Desde la perspectiva de la interculturalidad crítica que hemos adoptado para este análisis, una educación intercultural no solo debiera apuntar a generar un espacio de comunicación entre miradas culturales diversas, sino de cuestionar y transformar esas jerarquías. Desde ese horizonte, estos hallazgos procuran aportar elementos, por ejemplo, con respecto a necesidades específicas en la formación docente, que los propios participantes en el estudio manifestaron como demandas.

\section{Reflexiones finales}

Los enunciados que priman en las tramas narrativas de docentes, asistentes de la educación y directivos de estas escuelas interpeladas en su labor pedagógica por la presencia de estudiante migrantes, ligados al enfoque de los derechos humanos, las ideas de inclusión, la de adaptación, aporte a la diversidad e hibridación, remiten a una instalación acrítica de la idea de interculturalidad en el sistema educativo chileno que termina siendo funcional a un sistema educativo monocultural y socioeconómicamente desigual. Esta instalación, además, no ha sido sistemática, es decir, no parece el resultado de un impulso dirigido desde el nivel central del Estado, sino más bien de mensajes confusos y desarticulados que atraviesan las comunidades educativas. 
Esta forma de instalación se relaciona, además, con algunos importantes silencios en las narrativas relevadas. Uno de ellos es la ausencia de tematización de la interculturalidad como un enfoque capaz de cuestionar jerarquías sociales emparentadas con nuestra historia colonial; el otro, la no consideración de la dimensión autorreflexiva y autocrítica de la interculturalidad, en tanto que implica la disposición y apertura permanente a cuestionar las propias prácticas y los propios discursos, a cuestionarnos su arbitrariedad. Es necesario, entonces, transformar el carácter declarativo del principio de interculturalidad en el sistema educativo chileno, considerado como principio en la Ley General de Educación $(20370,2009)$ y la Ley de Inclusión, y utilizarlo estratégicamente para una materialización no funcional, si es que esto es posible en sistemas educativos como los que conocemos, es decir, creados para generar espacios comunes y relativamente neutros en sociedades diversas.

Esta materialización no puede depender de la buena voluntad de los profesores, asistentes y directores, que, como pudimos observar en el trabajo de campo, son quienes desde su sensibilidad y buena voluntad han estado respondiendo a los desafíos derivados de la llegada creciente de estudiantes migrantes al sistema educativo nacional. Como sostiene Walsh (2002), este no es un asunto de voluntad personal, sino un problema enraizado en relaciones de poder. Tampoco puede depender de la escuela por sí sola:

[La interculturalidad] va más allá de la búsqueda de reconocimiento o de inclusión porque apela a cambios profundos en todas las esferas de la sociedad y forma parte de una política cultural oposicional dirigida a la sociedad en su conjunto que aporta [...] "a la construcción de una propuesta civilizatoria alternativa, a un nuevo tipo de estado y a una profundización de la democracia" (Walsh, 2002, p. 3).

Pero, aunque es una tarea que excede a la escuela, tiene en ella un escenario decisivo, en el que se construyen importantes herramientas para lograrla. Es desde esa relevancia que nos interpelan los discursos identificados, en la medida en que, en su materialización en prácticas pedagógicas, pueden impedir o habilitar las transformaciones que requiere el sistema educativo para contribuir en el avance hacia una democracia radical.

\section{Agradecimientos y aclaraciones}

Se agradece el valioso trabajo de Tatiana Aguirre como asistente de esta investigación, así como los comentarios de los evaluadores del artículo. 
Las opiniones que se presentan en esta publicación, así como los análisis e interpretaciones, son de exclusiva responsabilidad de los autores, y no reflejan necesariamente la opinión del Ministerio de Educación.

\section{Sobre los autores}

María Fernanda Stang-Alva es investigadora del Centro de Investigación en Ciencias Sociales y Juventud, de la Universidad Católica Silva Henríquez, Chile. Es doctora en Estudios Sociales de América Latina.

Andrea Maureen Riedemann-Fuentes es socióloga, magíster en Educación Intercultural y doctora en Ciencias Históricas y Culturales. Está abocada a temas de diversidad cultural, racismo y educación.

Carolina Stefoni-Espinoza es socióloga y académica del Centro Sociedad Tecnológica y Futuro Humano de la Universidad Mayor, e investigadora del Centro de Estudio de Conflicto y Cohesión Social (COES), Chile.

Javier Corvalán-Rodríguez es antropólogo y doctor en Sociología, especialista en Sociología de la Educación y Política Educativa.

\section{Referencias}

Arfuch, L. (2002). El espacio biográfico. Dilemas de la subjetividad contemporánea. Buenos Aires: Fondo de Cultura Económica.

Arfuch, L. (2016). Subjetividad, memoria y narrativas: una reflexión teórica y política en el campo de la educación. magis, Revista Internacional de Investigación en Educación, 9(18), 227-244. Recuperado de https://dialnet. unirioja.es/servlet/articulo?codigo $=5762692$

Armijo-Cabrera, M. (2018). Deconstruyendo la noción de inclusión: un análisis de investigaciones, políticas y prácticas en educación. Revista Electrónica Educare (Educare Electronic Journal), 22(3), 1-26. Recuperado de https://www.scielo.sa.cr/scielo.php?script=sci_abstract\&pid=S140942582018000300151\&lng=en\&nrm=iso\&tlng=es

Blanco, R. (2006). La equidad y la inclusión social: uno de los desafíos de la educación y la escuela hoy. REICE. Revista Iberoamericana sobre Calidad, Eficacia y Cambio en Educación, 4(3), 1-15. Recuperado de https://revistas. uam.es/index.php/reice/article/view/10083/10191

Booth, T. \& Ainscow, M. (2004). Índice de inclusión: desarrollando el aprendizaje y la participación en las escuelas. Santiago de Chile: Unesco/OREALC.

Castro, E. (2004). El vocabulario de Michel Foucault. Un recorrido alfabético por sus temas, conceptos y autores. Buenos Aires: Prometeo/Universidad Nacional de Quilmes.

Consejo Latinoamericano de Ciencias Sociales (Clacso). (2012). Enunciado. OSAL, Observatorio Social de América Latina, XIII(31). Recuperado de https://www. clacso.org.ar/clacso/novedades_editoriales/libros_clacso/libro_detalle. php? orden $=$ nro_orden\&id_libro $=683 \&$ pageNum_rs_libros=0\&totalRows rs_libros $=654 \&$ orden $=$ nro_orden 
De Sousa Santos, B. (2002). Hacia una concepción multicultural de los derechos humanos. El Otro Derecho, 28, 59-83. Recuperado de http://www.uba.ar/ archivos_ddhh/image/Sousa\%20-\%20Concepci\%C3\%B3n\%20multicultu ral\%20de\%20DDHH.pdf

Diez, M. L. (2004). Reflexiones en torno a la interculturalidad. Cuadernos de Antropología Social, (19), 191-213. Recuperado de http://www.redalyc.org/ pdf/1809/180913911012.pdf

Fernández, M. P. (2018). Mapa del estudiantado extranjero en el sistema escolar chileno (2015-2017). Documento de trabajo N. . 12. Santiago: Mineduc.

Ferrajoli, L. (1999). Derechos y garantías. La ley del más débil. Madrid: Trotta.

Ferrão-Candau, V. (2010). Educación intercultural en América Latina: distintas concepciones y tensiones actuales. Estudios Pedagógicos, XXXVI(2), 333342. Recuperado de https://scielo.conicyt.cl/pdf/estped/v36n2/art19.pdf

Gibbs, G. (2012). El análisis de datos cualitativos en investigación cualitativa. Madrid: Morata.

Guilherme, M. \& Dietz, G. (2014). Diferencia en la diversidad: perspectivas múltiples de complejidades conceptuales multi, inter y transculturales. Estudios sobre las Culturas Contemporáneas, XX(40), 13-36. Recuperado de http:// www.redalyc.org/articulo.oa?id $=31632785002$

Jiménez, A. (2012). Migraciones, convivencia y educación intercultural. San José: Ministerio de Educación Pública.

Jiménez, F., Aguilera, M., Valdés, R. \& Hernández, M. (2017). Migración y escuela: análisis documental en torno a la incorporación de inmigrantes al sistema educativo chileno. Psicoperspectivas, 16(1), 105-116. Recuperado de http:// www.psicoperspectivas.cl/index.php/psicoperspectivas/article/viewFile/ 940/608

Laclau, E. \& Mouffe, C. (1987). Hegemonía y estrategia socialista. México: Siglo XXI. Lagos, C. (2015). El Programa de Educación Intercultural Bilingüe y sus resultados: ¿perpetuando la discriminación? Pensamiento Educativo. Revista de Investigación Educacional Latinoamericana, 52(1), 84-94. Recuperado de http://pensamientoeducativo.uc.cl/files/journals/2/articles/676/public/6762138-1-PB.pdf

Ley 20370 . Establece la Ley General de Educación. Recuperado de https://www. leychile.cl/Navegar?idNorma $=1006043$

Ley 20845 . De inclusión escolar que regula la admisión de los y las estudiantes, elimina el financiamiento compartido, y prohíbe el lucro en establecimientos educacionales que reciben aporte del Estado. Recuperado de: https:// www.leychile.cl/Navegar?idNorma $=1078172$

López, L. (2001). La cuestión de la interculturalidad y la educación latinoamericana. En Unesco-Santiago, Análisis de Prospectivas de la Educación en la Región de América Latina y el Caribe, Seminario sobre Prospectivas de la Educación en la Región de América Latina y el Caribe, Santiago, 23-25 de agosto de 2000 (pp. 382-406). Santiago: Unesco.

Martínez, J. \& Orrego, C. (2016). Nuevas tendencias y dinámicas migratorias en América Latina y el Caribe. Población y Desarrollo, 114. Santiago: Cepal. Recuperado de https://www.cepal.org/es/publicaciones/39994-nuevastendencias-dinamicas-migratorias-america-latina-caribe 
Ministerio de Desarrollo Social. (2016). Metodología de medición de pobreza multidimensional con entorno y redes. Serie Documentos Metodológicos Casen N. ${ }^{\circ}$ 32. Santiago. Recuperado de http://observatorio.ministeriodesa rrollosocial.gob.cl/casen-multidimensional/casen/docs/Metodologia_de Medicion_de_Pobreza_Multidimensional.pdf

Ministerio de Educación. (s. f). Política nacional de estudiantes extranjeros 20182022. Santiago: Mineduc. Recuperado de https://migrantes.mineduc.cl/wpcontent/uploads/sites/88/2018/06/POLITICA-NACIONAL-EE-Final-1-1.pdf

Ministerio de Educación. (2015). Orientaciones para la revisión y actualización del Proyecto Educativo Institucional. Santiago: Autor.

Ministerio de Educación. (2017). Orientaciones técnicas para la inclusión educativa de estudiantes extranjeros. Santiago: Mineduc. Recuperado de https:// www.ayudamineduc.cl/sites/default/files/orientaciones-estudiantes-extran jeros-21-12-17.pdf

Montecinos, C. (2004). Analizando la política de educación intercultural bilingüe en Chile desde la educación multicultural. Cuadernos Interculturales, 2(3), 25-32. Recuperado de http://www.redalyc.org/articulo.oa?id=55200304

Neufeld, M. R. \& Thisted, J. A. (Comps.). (1999). "De eso no se habla...". Los usos de la diversidad en la escuela. Buenos Aires: Eudeba.

Novaro, G. (2006). Educación intercultural en la Argentina: potencialidades y riesgos. Cuadernos Interculturales, 4(7), pp. 49-60. Recuperado de https:// www.redalyc.org/pdf/552/55200704.pdf

Novaro, G. (2011). La interculturalidad en debate. Experiencias formativas y procesos de identificación en niños indígenas y migrantes. Buenos Aires: Biblos.

Observatorio Social. (s. f.). Encuesta Casen 2017. Recuperado de http://observa torio.ministeriodesarrollosocial.gob.cl

Organización Internacional para las Migraciones (OIM). (2017). World Migration Report 2018. Ginebra: Autor. Recuperado de https://publications.iom.int/ es/books/world-migration-report-2018

Quijano, A. (2000). Colonialidad del poder y clasificación social. Journal of WorldSystem Research, XI(2), 342-386.

Riedemann, A. (2008). La educación intercultural bilingüe en Chile: Lampliación de oportunidades para alumnos indígenas? Indiana, 25, 169-193. Recuperado de https://www.iai.spk-berlin.de/fileadmin/dokumentenbibliothek/ Indiana/Indiana_25/Indiana_25_169-193_Riedemann.pdf

Riedemann, A. \& Stefoni, C. (2015). Sobre el racismo, su negación, y las consecuencias para una educación anti-racista en la enseñanza secundaria chilena. Polis, Revista Latinoamericana, 14(42), 191-216. Recuperado de https://scielo. conicyt.cl/scielo.php?script=sci_arttext\&pid=S0718-65682015000300010

Rodríguez-Cruz, M. (2016). ¿Reafirmación identitaria o blanqueamiento? Educación intercultural bilingüe, Sumak Kawsay y matriz productiva en el sistema educativo ecuatoriano. En F. Gervasi (Coord.), Diversidades. Perspectivas multidisciplinarias para el estudio de la interculturalidad y el desarrollo social (pp. 311-353). México: Universidad Autónoma de Coahuila y Ediciones de Laurel.

Sinisi, L. (1999). La relación "nosotros-otros" en espacios escolares "multiculturales". Estigma, estereotipo y racialización. En M. R. Neufeld \& J. A. Thisted 
(Comps.), "De eso no se habla...". Los usos de la diversidad en la escuela. Buenos Aires: Eudeba.

Smith-Castro, V., Araya, M. A. \& Peña, L. (2009). ¿Costa Rica solidaria? Actitudes hacia la migración y los inmigrantes. Revista Digital de la Maestría en Ciencias Penales de la Universidad de Costa Rica, 1, 519-534. Recuperado de https://revistas.ucr.ac.cr/index.php/RDMCP/article/view/12647

Soria, S. (2014). El "lado oscuro" del proyecto de interculturalidad-decolonialidad: notas críticas para una discusión. Tabula Rasa, (20), 41-64. Recuperado de http://www.scielo.org.co/pdf/tara/n20/n20a03.pdf

Stang, F. (2018). Fronteras, sexualidades y procesos de subjetivación. Migrantes LGTBIQ colombianos y peruanos en Santiago de Chile (tesis de doctorado). Universidad Nacional de Córdoba, Córdoba, Argentina.

Stefoni, C., Stang, F. \& Riedemann, A. (2016). Educación e interculturalidad en Chile: un marco para el análisis. Relaciones Internacionales, 48(185), 153-182. Recuperado de https://revistaei.uchile.cl/index.php/REl/article/view/44534

Tijoux, M. E. (2013a). Las escuelas de la inmigración en la ciudad de Santiago: elementos para una educación contra el racismo. Polis, Revista Latinoamericana, 12(35), 287-307. Recuperado de https://scielo.conicyt.cl/scielo. php?script=sci_arttext\&pid=S0718-65682013000200013

Tijoux, M. E. (2013b). Niños(as) marcados por la inmigración peruana: estigma, sufrimientos, resistencias. Convergencia. Revista de Ciencias Sociales, 20(61), 83-104. Recuperado de https://convergencia.uaemex.mx/article/view/1051

Tijoux, M. E. (2016). Racismo en Chile. La piel como marca de la inmigración. Santiago: Universitaria.

Tubino, F. (2005). La interculturalidad crítica como proyecto ético-político. Ponencia presentada en el Encuentro Continental de Educadores Agustinos, Lima, 24-28 de enero.

Walsh, C. (2002). (De) Construir la interculturalidad. Consideraciones críticas desde la política, la colonialidad y los movimientos indígenas y negros en el Ecuador. En N. Fuller, Interculturalidad y política. Desafíos y posibilidades (pp. 115-142). Lima: Red para el Desarrollo de las Ciencias Sociales en el Perú.

Walsh, C. (2009). Interculturalidad crítica y educación intercultural. Ponencia presentada en Interculturalidad y Educación Intercultural, La Paz, 9-11 de marzo.

Walsh, C. (2011). Etnoeducación e interculturalidad en perspectiva decolonial. En Centro de Desarrollo Étnico (Cedet), Desde adentro. Etnoeducación e Interculturalidad en el Perú y América Latina. Lima: Bellido. 